\title{
Temporal and spatial variation in macrofauna community composition imposed by ghost shrimp Callianassa filholi bioturbation
}

\author{
Katrin Berkenbusch ${ }^{1, *}$, Ashley A. Rowden ${ }^{2}$, P. Keith Probert ${ }^{1}$ \\ ${ }^{1}$ Department of Marine Science, University of Otago, PO Box 56, Dunedin, New Zealand \\ ${ }^{2}$ Benthic Ecology Research Group, Department of Biological Sciences, University of Plymouth, Drake Circus, Plymouth, \\ Devon PL 8AA, United Kingdom
}

\begin{abstract}
The impact of bioturbation by the burrowing ghost shrimp Callianassa filholi on benthic community composition was examined in relation to seasonal and small-scale spatial changes. Sites of naturally occurring low and high densities of $C$. filholi on an intertidal sandflat represented differences in bioturbation activity throughout the year. Univariate and multivariate analyses showed significant differences in community composition between high- and low-density sites. The total number of species and total number of individuals were lower at high-density sites. A corophiid amphipod, Paracorophium excavatum and a small bivalve, Perrierina turneri, appeared to have the greatest discriminating significance with lower abundances of both species at sites of high $C$. filholi density. Even though differences between sites of different density persisted throughout the year, the impact of bioturbation depended on season. Bioturbation had the highest maximum correlation to changes in macrofaunal community composition in winter, spring and, in association with seagrass biomass (Zostera novazelandica), in autumn. During summer, however, seagrass biomass contributed the most to observed differences and appeared to compensate for generally high bioturbation activity. The results imply that bioturbation impacted on macrofauna community composition over a small spatial scale and, although its impact varied seasonally, imposed patterns persisted throughout the year. As such, $C$. filholi can be considered a keystone species.
\end{abstract}

KEY WORDS: Macrofauna community $\cdot$ Bioturbation $\cdot$ Callianassa $\cdot$ Intertidal sandflat $\cdot$ Small scale

\section{INTRODUCTION}

Benthic community structure of soft sediment environments in tropical and temperate regions can be greatly affected by bioturbation (e.g. Myers 1977, Murphy \& Kremer 1992). Feeding and burrowing activities by a variety of bioturbators (e.g. fish, hemichordates, polychaetes, holothurians, crustaceans) can cause substantial sediment disturbance in intertidal and subtidal habitats (e.g. Rhoads \& Young 1971, Grant 1983). Resulting biological implications include both negative and positive effects for the abundance of associated organisms (Peterson 1977, Suchanek 1983, DeWitt \& Levinton 1985, Townsend \& Fonseca 1998). Suscepti-

\footnotetext{
•E-mail:katrin berkenbusch@stonebow.otago.ac.nz
}

bility to sediment disturbance varies among infaunal species, most likely related to feeding mode, size and motility of the organisms concerned, and is reflected in the overall benthic community composition (Brenchley 1981, Wilson 1981).

Despite the importance of bioturbation, few studies have examined the relationship between both temporal and spatial variations in such biological disturbance and benthic community composition (e.g. Posey 1986). Although it has been shown that rates of sediment turnover (as a measure of bioturbation) differ significantly over time (Retraubun et al. 1996), little information is available concerning this often seasonal variation and the changes it imposes on benthic community structure. Furthermore, densities of bioturbators often vary on a small scale (over 10 s of metres) 
within one location (Swinbanks \& Murray 1981), which is likely to influence the occurrence of associated fauna.

Due to their often high population densities and relatively deep burrows, callianassid shrimps (also referred to as ghost or mud shrimps) have been identified as important infaunal bioturbators with potentially the greatest effects over the largest depth range (AbuHilal et al. 1988, Swift 1993). Callianassid burrows are associated with unconsolidated mounds on the sediment surface, which are sources of mobile sediment in stable bottom areas, thus promoting sediment instability (Aller \& Dodge 1974, Roberts et al. 1982). Furthermore, the sediment turnover activity of temperate species has been shown to differ significantly over time (Stamhuis et al. 1997, Rowden et al. 1998, Berkenbusch \& Rowden 1999). However, most studies to date have examined the impact of callianassid shrimp bioturbation under laboratory conditions and/or involved experimental exclusion of ghost shrimp (by defaunation or cages, e.g Bird 1982, Tamaki 1988, Dittmann 1996), thus potentially introducing experimental artefacts. By contrast, the present study adopted a so-called 'natural experimental' approach to examine the macrofaunal community composition in relation to temporal and spatial variations in bioturbation by the burrowing ghost shrimp Callianassa filholi. The aims of the study were to determine the macrofauna community composition in relation to (1) natural differences in the density of $C$. filholi, i.e. bioturbation on a relatively small but ecologically meaningful spatial scale, and (2) sea- sonal changes in sediment turnover activity, i.e. at a pronounced temporal scale ascertained by a previous study (Berkenbusch \& Rowden 1999).

Note: The systematic status of Callianassa filholi Milne-Edwards, 1878 is currently under review.

\section{MATERIALS AND METHODS}

Sample collection and analysis. The study site was on an intertidal sandflat in Otago Harbour, south-eastern New Zealand $\left(45^{\circ} 30^{\prime} \mathrm{S}, 170^{\circ} 42^{\prime} \mathrm{E}\right.$ ) (Fig. 1A). Prior to sampling, 4 sites $(4 \times 4 \mathrm{~m})$ were arbitrarily chosen to each represent low and high Callianassa filholi densities.

Initial selection of density groupings was based on an average of 2.5 sediment expulsion mounds $\mathrm{m}^{-2}$ for low density sites, and an average of at least twice as many for high density sites. Pairs of sites of the different density groupings were located on the sandflat throughout the tidal range of the shrimp's occurrence (Fig. 1B) (Berkenbusch \& Rowden 1998 1999). The position of sites on the sandflat was established by triangulation in order to allow for subsequent relocation. Sampling was conducted after a period of calm weather (at least $1 \mathrm{wk}$ ) to minimise obliteration of mounds by wind and wave action. Samples were collected on 4 occasions-November 1997, January, April, June 1998, representing the seasons of spring, summer, autumn and winter respectively. Spring and summer have previously been identified as times of

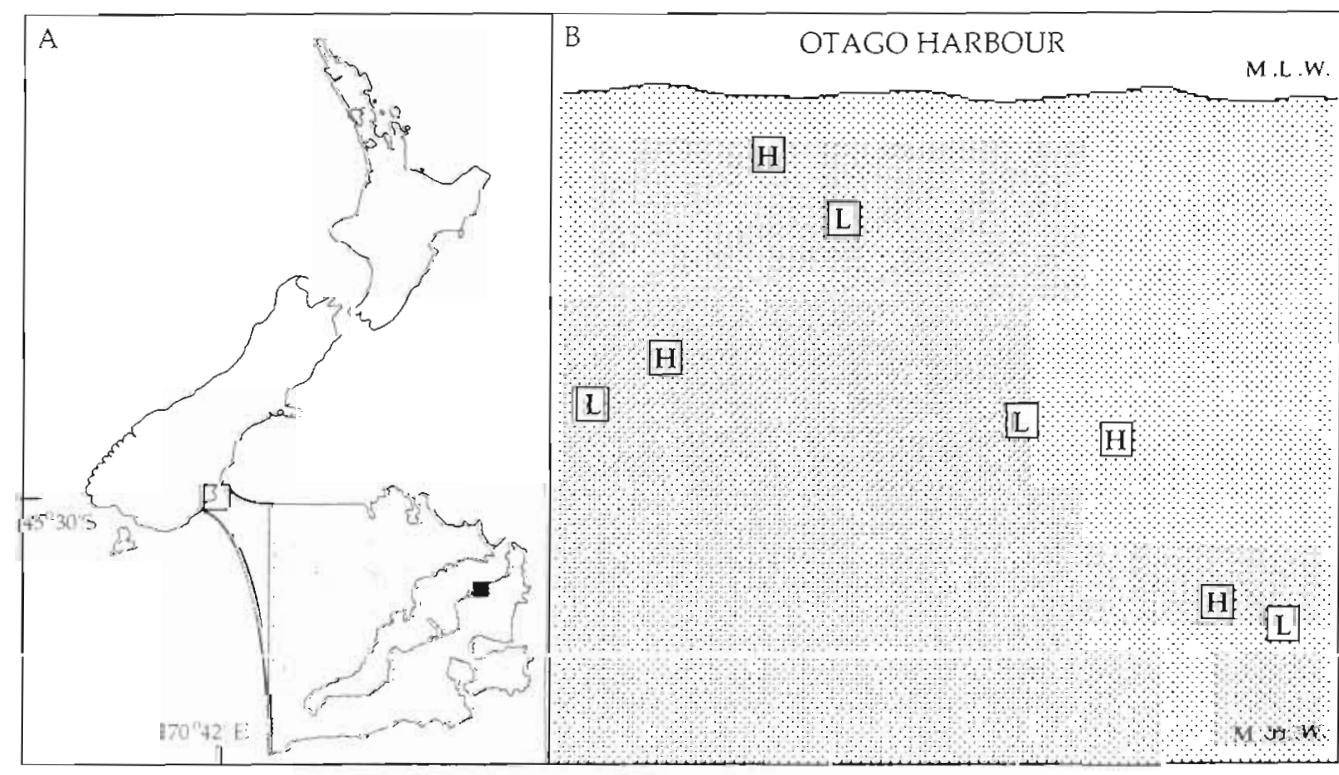

Fig. 1. (A) Location of the intertidal sandflat (-) in south-eastern New Zealand within Otago Harbuur and (B) schematic layout of macrofauna sampling sites of low (L) and high (H) Callianassa filholi density (M.L.W. and M.H.W.: mean low and high water respectively) 
Table 1. Results from the 2-way crossed ANOVA (factors: low and high Callianassa filholi density, time and interactions) for community measures and environmental factors at the intertidal sandflat (all seasons: November. 1997 to June 1998 ) (Significant values in bold)

\begin{tabular}{|c|c|c|c|c|c|c|}
\hline & \multicolumn{2}{|c|}{ Density } & \multicolumn{2}{|c|}{ Time } & \multicolumn{2}{|c|}{ Density $\times$ Time } \\
\hline & $F$ & $\mathrm{p}$ & $F$ & $\mathrm{p}$ & $F$ & $\mathrm{p}$ \\
\hline Total number of species & 1.1645 & 0.2823 & 11.685 & $\leq 0.0001$ & 3.9886 & $\leq 0.0001$ \\
\hline Total number of individuals & 3.3706 & 0.0684 & 5.3303 & 0.0016 & 3.4851 & 0.0175 \\
\hline Evenness $\left(\mathrm{J}^{\prime}\right)$ & 0.03467 & 0.8525 & 2.2814 & 0.0817 & 2.6278 & 0.0525 \\
\hline Seagrass biomass & 1.0819 & 0.1796 & 2.0118 & 0.1148 & 0.47471 & 0.7004 \\
\hline Mean sediment grain size & 0.49609 & 0.4823 & 4.9778 & 0.0026 & 0.65995 & 0.578 \\
\hline Organic content & 2.0091 & 0.1585 & 0.90815 & 0.4388 & 1.4011 & 0.2449 \\
\hline Sediment sorting & 0.2792 & 0.5980 & 3.7591 & 0.0123 & 0.19136 & 0.9022 \\
\hline Mound density & 17.364 & 0.0004 & 10.083 & 0.0002 & 0.45351 & 0.7173 \\
\hline Mound volume & 1.8916 & 0.1711 & 21.188 & $\leq 0.0001$ & 0.25814 & 0.8554 \\
\hline
\end{tabular}

high sediment turnover activity, whilst autumn and winter are times of low bioturbatory activity (Berkenbusch \& Rowden 1999). On each sampling occasion, the number of mounds was recorded for each site and 5 haphazard cores $(10 \mathrm{~cm} \varnothing, 10 \mathrm{~cm}$ depth) were collected. Adjacent to each macrofauna core, the volume of the closest mound (within $30 \mathrm{~cm}$ distance) was noted, and sediment cores were taken $(3 \mathrm{~cm} \varnothing, 10 \mathrm{~cm}$ depth) for granulometry and organic content analysis.

Faunal samples were washed on $500 \mu \mathrm{m}$ mesh and material retained on the sieve was fixed in $10 \%$ buffered formalin/seawater and stained with rose bengal. Macrofaunal specimens were identified to family level and thereafter to putative species (with the exception of Maldanidae). Seagrass material (Zostera novazelandica) was separated from faunal samples, dried $\left(24 \mathrm{~h}\right.$ at $\left.70^{\circ} \mathrm{C}\right)$ and weighed. Sediment grain size was determined by sieving at $1 \phi$ intervals from $1 \mathrm{~mm}$ to $63 \mu \mathrm{m}$ (Buchanan 1984), and sediment sorting was ascertained using the program Rapid Sediment Analysis v. 7.1 (developed by the University of Waikato). Organic content was determined by loss of weight on ignition $\left(4 \mathrm{~h}\right.$ at $500^{\circ} \mathrm{C}$ ).

Data analysis. Community composition was examined using the software package PRIMER, which has been specifically designed for the study of community structure (see Clarke \& Warwick 1994). Univariate measures (total number of individuals, total number of species and index for evenness) were calculated utilising DIVERSE (Warwick et al. 1990a). Data were graphically assessed for normality (Zar 1984) and, due to non-significant block effects, differences in community measures and environmental parameters were tested by applying 2-way crossed ANOVA (involving ghost shrimp density and time as factors and including interactions). For multivariate analysis, a ranked triangular similarity matrix was derived based on the Bray-Curtis index on $\mathcal{V}$-transformed data. For each sampling occasion, differences between sites within and between low and high shrimp density grouping were tested by 2-way crossed ANOSIM permutations (Warwick et al. 1990b). Taxa contributing to the dissimilarities between density groupings were determined by the similarity percentages procedure SIMPER (Clarke 1993). The relationship between multivariate community structure and environmental parameters was investigated using the BIOENV procedure (Clarke \& Ainsworth 1993). Environmental parameters used were seagrass biomass, mound density, mound volume, sediment grain size, sorting, and organic content (the latter 2 were $\log$ transformed, natural $\log$ ). Mound density and mound volume were used as proxy measures for ghost shrimp bioturbatory activity.

It is important to note that one site was missed during sampling in April, resulting in a lower number of possible permutations and subsequently less power in the ANOSIM analysis. However, the remaining number of permutations was sufficient to accept the significance of detected differences for that sampling occasion.

\section{RESULTS}

\section{Univariate analysis}

The total number of species and total number of individuals changed significantly over time and between density groupings of Callianassa filholi over time (Table 1). Both community measures decreased in autumn and winter (April and June), particularly at sites of high C. filholi density (Fig. 2). Evenness did not change significantly between density groupings, or over time (Table 1, Fig. 2). Of the environmental parameters (Table 2), seagrass biomass and organic content showed no significant differences between density groupings or over time, but sediment grain size and sorting changed significantly over time, with the sorting coefficient being significantly higher for both den- 
sity groupings in summer (January) (Table 1). Also, both mound density and mound volume differed significantly over time, with significant differences in mound density between sites of low and high ghost
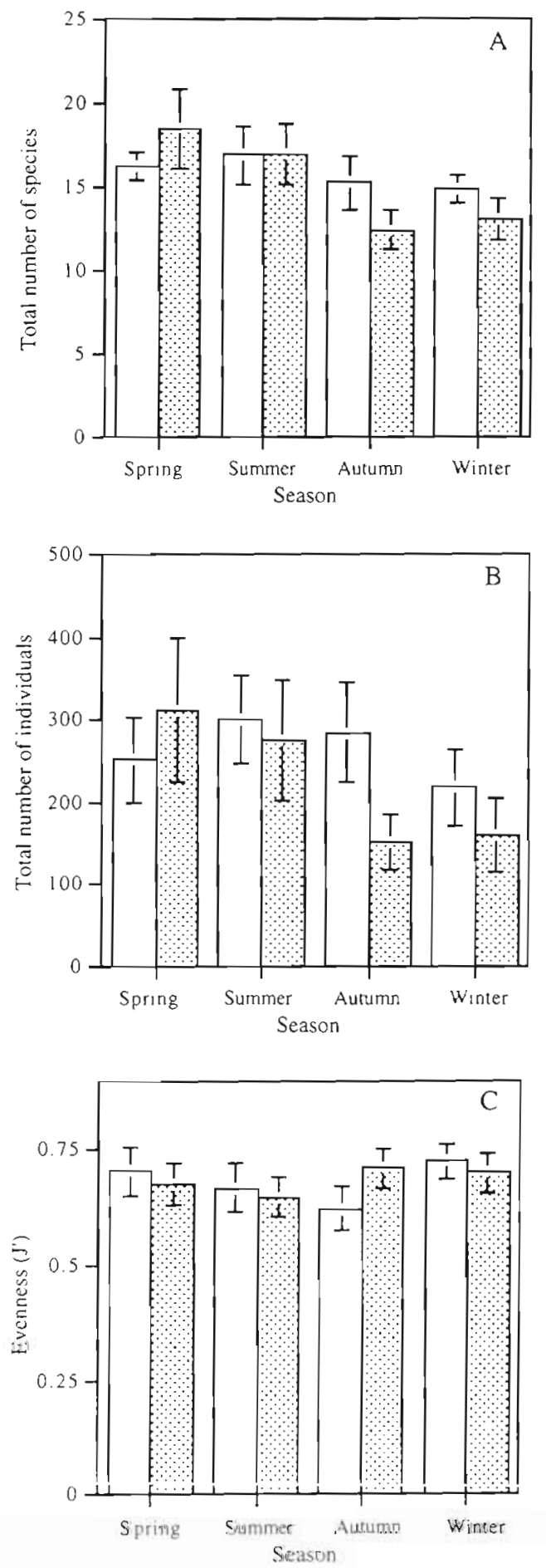

Fig. 2. (A) Mean values for total number of species, (B) total number of individuals, and $(C)$ evenness for all seasons. Sites of low (open bars) and high (shaded bars) Callianassa filholl density (vertical bars $= \pm 2 \mathrm{SE}$ ) shrimp density each season (Table 1). Values for mound density and mound volume were highest in summer, and both measures decreased markedly in autumn and winter (Fig. 3).
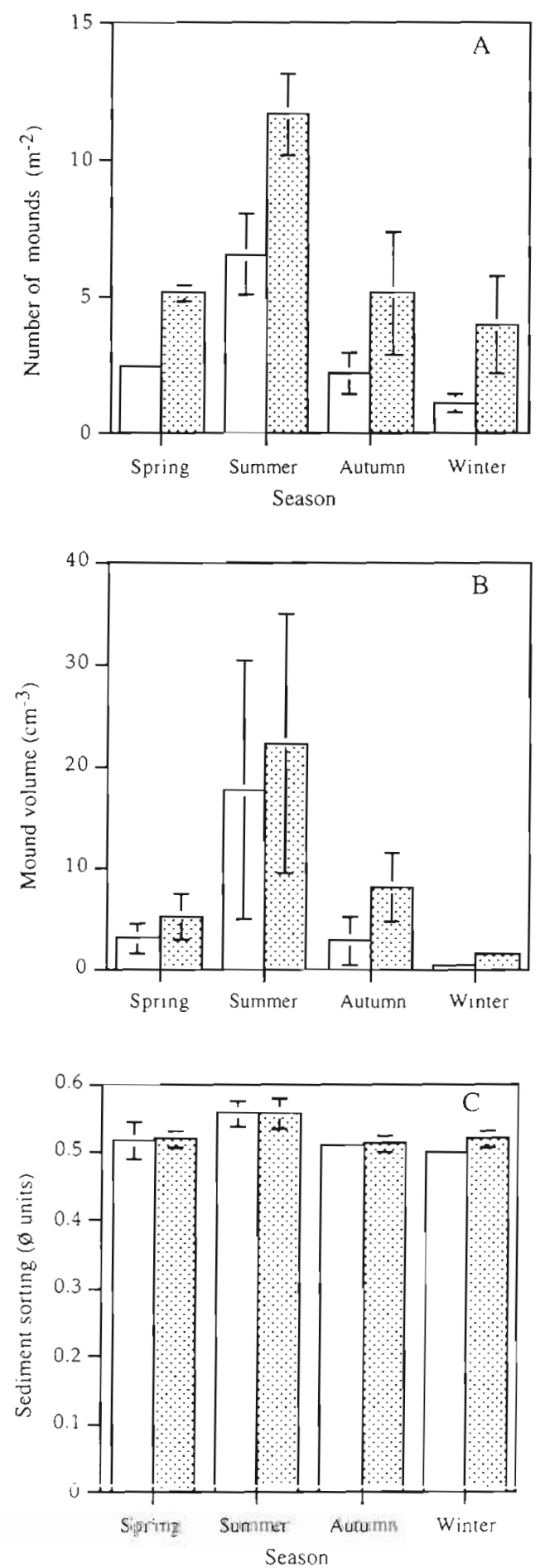

Fig. 3. (A) Mean values for number of mounds, (B) mound volume and (C) sediment sorting for all seasons. Sites of low lopen bars) and high (shaded bars) Callianassa filholi density (vertical bars $= \pm 2 \mathrm{SE}$ ) 


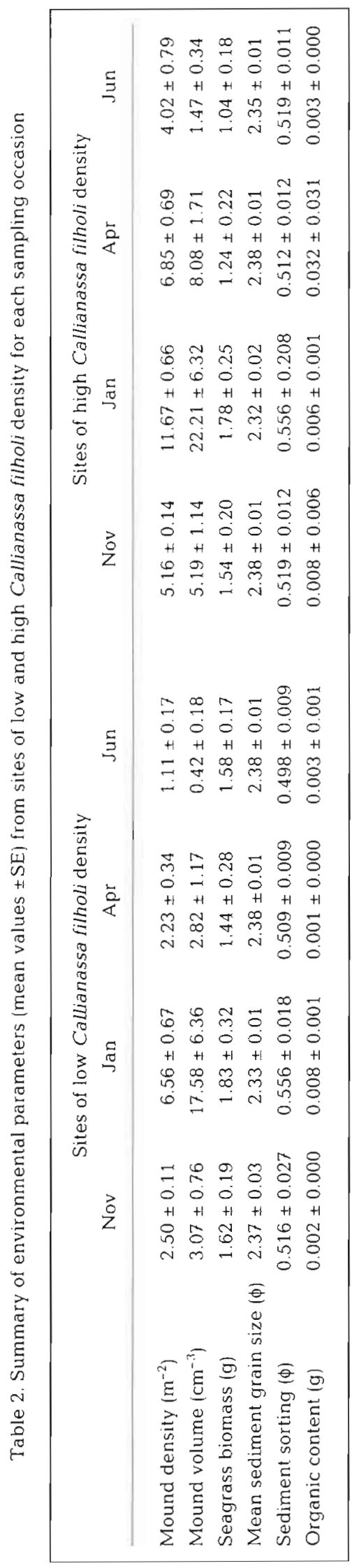

\section{Multivariate analysis}

Two-way crossed ANOSIM permutation tests for each season indicated a significant difference in community structure between and, to a greater extent, within ghost shrimp density groupings (Table 3). Analysis of these differences each season using SIMPER showed dissimilarity percentages between low and high shrimp density sites and identified organisms contributing to those dissimilarities; out of a total of 56 species, 6 contributed the most $(50 \%)$ to observed dissimilarities: the burrowing amphipod Paracorophium excavatum and the small bivalve Perrierina turneri appeared to have the most influence on dissimilarities throughout all seasons and consistently high ratio values $\left(\bar{\delta} \mathrm{i} / \mathrm{SD}_{\delta}\right)$ confirmed their significance as discriminating species (Clarke 1993). Both species showed higher densities at sites of low ghost shrimp density (Table 4)

BIOENV results indicated that mound density and seagrass biomass were the main parameters explaining the macrofauna composition. Mound density accounted for maximum rank correlation in spring $\left(\rho_{\mathrm{w}}=\right.$ 0.266 ), whilst seagrass biomass appeared to be the most important parameter in summer $\left(\rho_{w}=0.378\right)$. In autumn, the combination of both mound density and seagrass biomass gave the greatest rank correlation $\left(\rho_{w}=0.435\right)$, whilst mound density was the most significant factor in winter $\left(\rho_{w}=0.435\right)$.

\section{DISCUSSION}

Significant changes in mound density and expulsion mound volume, both monitored as proxy measures for spatial and temporal changes in sediment turnover activity, confirmed anticipated variation in Callianassa filholi bioturbation. Indeed, the study showed that the number and volume of mounds can be useful parameters for evaluating relative changes in bioturbation activity by a temperate callianassid shrimp (see also Berkenbusch \& Rowden 1998, 1999).

Dissimilarities in community structure between sites of low and high Callianassa filholi density showed that although selected sites were part of one intertidal sandflat, benthic community composition altered in a relatively small, yet significant, way in space and time. Differences in community composition between areas of different shrimp density were evident over 10 s of metres and months. Spatial and temporal patterns in shrimp density and sediment turnover have been shown to persist over the entire area of the sandflat which C. filholi inhabits (Berkenbusch \& Rowden 1998 1999). The cause of changes in community structure appeared to be related to the bioturbatory activity of $C$. 
Table 3. Results from the 2-way crossed ANOSIM test for differences in macrofaunal composition between sites of low and high Callianassa filholi density and between sites within each density grouping for each season $(R$ : comparative measure of the degree of separation of sites) (significant values in bold)

\begin{tabular}{|lcccccccc}
\hline Factor & \multicolumn{2}{c}{ November } & \multicolumn{2}{c}{ January } & April & & June \\
& $R$ & $p$ & $R$ & $p$ & $R$ & $p$ & $R$ \\
\hline Density (low vs high) & 0.683 & $\leq 0.001$ & 0.594 & $\leq 0.001$ & 0.633 & $\leq 0.001$ & 0.608 & $\leq 0.001$ \\
Sites & 0.783 & $\leq 0.001$ & 0.821 & $\leq 0.001$ & 0.722 & $\leq 0.001$ & 0.755 & $\leq 0.001$ \\
\hline
\end{tabular}

Table 4. Mean abundance $(\alpha)$ and dissimilarity (DS) of macrofaunal species averaged for and between high $\left(\alpha_{H}\right)$ and low $\left(\alpha_{L}\right)$ shrimp density sites for each season as calculated by SIMPER. Species are ranked in order of their percentage contribution $(\delta i \%)$ to the average Bray-Curtis dissimilarity between both density groupings, including the ratio $\left(\bar{\delta} \mathrm{i} / \mathrm{SD}_{\hat{\delta}_{1}}\right)$ and expressed as cumulative percentage $(\Sigma \delta \mathrm{i} \%$ ) (cut-off to species list applied at $50 \%$ )

\begin{tabular}{|c|c|c|c|c|c|c|}
\hline & Species & $\alpha_{H}$ & $\alpha_{L}$ & $\delta i \%$ & Ratio & $\Sigma \delta \mathrm{i} \%$ \\
\hline \multirow[t]{6}{*}{ Nov, $D S=41.63 \%$} & Perrierina turner & 67.60 & 73.95 & 13.08 & 1.25 & 13.08 \\
\hline & Tanaldae 1 & 75.40 & 24.85 & 10.37 & 1.37 & 23.45 \\
\hline & Paracorophium excavatum & 36.00 & 43.35 & 8.69 & 1.34 & 32.14 \\
\hline & Syllidae 1 & 46.55 & 23.75 & 7.14 & 1.36 & 39.28 \\
\hline & Enchytraeidae & 11.90 & 18.10 & 5.29 & 1.18 & 44.57 \\
\hline & Tanaidae 2 & 6.45 & 3.90 & 4.47 & 1.49 & 49.04 \\
\hline \multirow[t]{5}{*}{$\mathrm{Jan}, \mathrm{DS}=43.75 \%$} & Paracorophium excavatum & 45.65 & 74.25 & 12.72 & 1.54 & 12.72 \\
\hline & Perrerina turnen & 43.55 & 91.60 & 12.69 & 1.52 & 25.41 \\
\hline & Syllidae 1 & 88.90 & 37.20 & 10.31 & 1.38 & 35.72 \\
\hline & Tanaldae 1 & 34.65 & 20.40 & 6.21 & 1.30 & 41.93 \\
\hline & Paracalliope novizealandiae & 7.10 & 12.70 & 4.74 & 1.54 & 46.66 \\
\hline \multirow[t]{4}{*}{ Apr, DS $=43.22 \%$} & Paracorophum excavatum & 28.33 & 100.85 & 16.44 & 1.74 & 16.44 \\
\hline & Syllidae 1 & 37.53 & 59.35 & 11.54 & 1.39 & 27.98 \\
\hline & Perrierina turnen & 33.80 & 44.15 & 9.90 & 1.37 & 37.88 \\
\hline & Enchytraeidae & 2.93 & 20.25 & 7.53 & 1.27 & 45.42 \\
\hline \multirow[t]{5}{*}{ Jun, DS $=43.45 \%$} & Paracorophum excavatum & 40.65 & 50.45 & 13.92 & 1.44 & 13.92 \\
\hline & Perrierina turnen & 35.10 & 41.85 & 11.04 & 1.38 & 24.96 \\
\hline & Enchytraeidae & 7.75 & 29.15 & 9.68 & 1.49 & 34.64 \\
\hline & Syllidae 1 & 38.95 & 40.20 & 7.72 & 1.28 & 42.36 \\
\hline & Syllidae 2 & 5.45 & 10.65 & 6.02 & 1.36 & 48.38 \\
\hline
\end{tabular}

filholi, the presence of Zostera novazelandica or a combination of both, depending on the season.

It can be assumed that the macrofaunal community as a whole is adapted to bioturbation as species of low tolerance to sediment turnover are likely to avoid sediments that contain large bioturbators (Woodin 1985). Such general adaptation of the benthic community is indicated at the present study site by the measure of evenness, for which no differences between sites of different shrimp density or over time were detected. Low values for the total number of species and total number of individuals in autumn and winter, particularly at sites of high Callianassa filholi density, can be oxplained by the cescation of recruitment which might compensate for the effect of disturbance during spring and summer. Multivariate dissimilarities in community structure occurred over a small scale on the study sandflat corresponding to bioturbation, implying that sediment disturbance exceeded tolerance levels at sites of high shrimp density.
Whilst few studies have investigated small-scale variations in bioturbation, Wilson (1981) noted that sediment disturbance by the large polychaete $A b a-$ renicola pacifica had a negative effect on the number of some tube-building species such as a small spionid polychaete. Also on a small spatial scale, the lugworm Arenicola marina and cockle Cerastoderma edule have been found to regulate the abundance of corophiid amphipods on tidal flats, but physical factors seemed to be more important over a large scale (Flach $\&$ de Bruin 1993). Following disturbance designed to stimulate a storm, patterns of macrobenthic recolonisation were different near (at the entrance) and away \{1 $1 \mathrm{~m}$ ) from burrows of the docapod crab Macroph thalmus hirtipes; although the same taxa were present, some common taxa, total number of taxa and toial number of individuals were significantly less abundant at the burrow entrance, which has been attributed to the disruption caused by $M$. hirtipes walking in and out of the burrows (Thrush 1988). With respect to cal- 
lianassid shrimp. Posey (1986) observed densities of several common macrofaunal species decreasing by an order of magnitude within a dense ghost shrimp bed in comparison to adjacent areas of low shrimp density. In agreement with these assessments of small-scale bioturbation, the findings of the present study imply that despite a general adaptation of the macrofauna community, bioturbation can change macrofaunal composition in small localised areas.

Spatial differences in community composition at the study site continued throughout all seasons, even though bioturbation declined significantly in colder months. Conversely, Myers (1977) found that the resilience of a spionid polychaete to a bioturbating holothurian, Leptosynapta tenuis, was linked to seasonal variation in sediment processing. That is, following recruitment in autumn, the spionids dominated numerically in winter, when sediment disturbance nearly ceased. Amphipods have been recorded to show seasonal variations in the effect of ghost shrimp density, exhibiting lower numbers when sediment turnover activity was high (Posey 1986). As a consequence, Posey (1986) speculated that natural reduction of bioturbation in winter, combined with migration by benthic fauna, produces a lesser impact on community structure. Whilst this would be reflected in smaller differences between areas of low and high shrimp densities, the present study controverts this view, as there was no significant alteration in impact on the macrofauna community with a decline in bioturbation. Instead, low sediment turnover activity during the colder months was accompanied by low abundance of macrofauna, so that the influence of bioturbation persisted at the same relative magnitude throughout the year.

Dissimilarities in macrofauna community structure were reflected in low abundances of both discriminating species Paracorophium excavatum and Perrierina turneri at sites of high shrimp density. Corophiid amphipods and bivalves have been shown previously to be susceptible to bioturbation. Sediment turnover by Arenicola marina and Cerastoderma edule led to a dramatic decrease in corophiid amphipods (Flach 1993), whilst the exclusion of ghost shrimp Neotrypaea californiensis resulted in a considerable increase in corophiid densities within 6 mo (Bird 1982). Sensitivity of corophiids to sediment turnover has been attributed to their tube-building behaviour, which is adversely affected by sediment disturbance (Brenchley 1981). Sediment disturbance can also have a deleterious effect on bivalves, interfering with feeding processes or causing (particularly small) bivalves to become disorientated within the sediment (Myers 1977. Murphy 1985). Furthermore, direct consumption and burial of newly recruited juvenile bivalves have been linked to the exclusion of bivalves at sites where ghost shrimp were abundant (Peterson 1977).

Whilst bioturbation appears to have a significant and explainable influence on the spatial variation of macrofauna community composition, multivariate analysis identified seagrass (Zostera novazelandica) biomass as also contributing to the structure of the associated community. However, the underlying mechanism for the seasonal importance of $Z$. novazelandica is unclear as there were no significant changes in its biomass either between shrimp density groupings or over time. A possible explanation for its relative influence on macrofauna community composition could be related to seasonal variation in above-ground growth (i.e. shoots and leaves), depending on light and temperature. Z. novazelandica biomass was revealed by the BIOENV analysis to best explain community patterns during the optimum seagrass growing season (summer) and, to a lesser extent, in autumn (when both light and temperature declined). A connection between above-ground growth and infaunal community composition has been made by Webster et al. (1998), who attributed community differences in areas of low and high $Z$. marina densities to the number of leaves per shoot and shoot density. As seagrass beds generally have higher numbers of species and individuals than unvegetated areas (Bostroem \& Bonsdorff 1997), an increase of above-ground growth of $Z$. novazelandica during summer possibly promoted the observed increase in these 2 community measures at sites of both density groupings in spite of high bioturbation rates. Therefore, $Z$. novazelandica may function as a 'buffer', in this case compensating for any possible negative effects of high sediment turnover activity by Callianassa filholi in warmer months.

Thus, it is possible from the present study to conclude that bioturbation by the ghost shrimp Callianassa filholi does impose small-scale spatial variation in macrofaunal community composition, and that any temporal variation is moderated by the seagrass Zostera novazelandica. However, natural experiments such as the present study cannot prove causality. Furthermore, it is evident from the values of the BIOENV analysis that bioturbation and seagrass biomass explain only part of the observed differences in community structure. Therefore, other factors must also be playing an important role. For example, predation has also been shown to impose small-scale differences in macrofaunal community measures for intertidal habitats (Thrush et al. 1994). In addition, the temporal changes in sediment sorting observed at the site hint at the role of physical parameters (e.g. waves). Such sediment variables have often been linked to large-scale patterns in community composition (Grant 1983). Flach \& de Bruin (1993), who identified the impact of bio- 
turbation on 2 amphipod species, attributed some of the impact to unknown factors operating over a large scale. Hence, it appears likely that bioturbation can be of primary importance on a small scale, whilst physical parameters are most likely to determine the macrofaunal community on a larger scale (Hall et al. 1993).

The identification of Callianassa filholi as an important bioturbator gives rise to the need for further studies; these could focus on the precise mechanism, possibly on an even smaller scale, by which spatial variation is imposed on the community composition (see Warwick et al. 1986). Furthermore, the present evidence suggests that $C$. filholi could be a singularly important species for structuring the sandflat macrofauna community - that is a keystone species (Paine 1966). Thus, the species requires further investigation, certainly considering the recent interest in applying the keystone species theory to soft sediments (Widdicombe \& A.usten 1998), and in the development of the ecosystem engineer concept (Jones et al. 1994), which allows for the assessment of the relative importance of various bioturbators to community structure.

Acknowledgements. The authors wish to thank staff at the Portobello Marine Laboratory for technical support and David Fletcher (Department of Mathematics and Statistıcs, University of Otago) for statistıcal advice. Thanks are extended to Graham Fenwick (NIWA, Christchurch) for the identification of amphipods. K.B. is particularly grateful to Tom Myers for help with fieldwork and assistance in operating software and to Simon Grove for useful discussions about PRIMER.

\section{LITERATLRE CITED}

A.bu-Hilal AM, Badran M, de Vaugelas J (1988) Distribution of trace elements in Callichirus laurae burrows and nearby sediments in the Gulf of Aqaba, Jordan (Red Sea). Mar Environ Res 25:233-248

Aller RC, Dodge RE (1974) Animal-sediment relations in a tropical lagoon Discovery Bay, Jamaica. J Mar Res 32 : $209-232$

Berkenbusch K, Rowden AA (1998) Population dynamics of the burrowing ghost shrimp Callianassa titholi on an intertidal sandflat in New Zealand. Ophelia 49:55-69

Berkenbusch K, Rowden AA (1999) Factors influencing sediment turnover by the burrowing ghost shrimp Callianassa tilholi (Decapoda: Thalassinidea). J Exp Mar Biol Ecol 283(2):283-292

Bird EW (1982) Population dynamics of the thalassinidean shrimps and their community effects through sediment modification. PhD thesis, University of Maryland, College Park

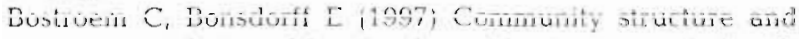
spatial variation of benthic invertebrates associated with Zostera marina (L,) beds in the northern Baltic Sea. I Sea Res 37:153-166

Brenchley CA (1981) Disturbance and community structure: an experimental study of biofurbation in marine softbottom environments. 3 Mar Res 39:767-790

Buchanan JB (1984) Sediment analysis. In: Holme NA, McIn- tyre AD (eds) Methods for the study of marine benthos. Blackwell, Oxford

Clarke KR (1993) Non-parametric multivariate analyses of changes in community structure. Aust J Ecol 18:117-143

Clarke KR, Ainsworth MA (1993) A method of linking multivariate community structure to environmental variables. Mar Ecol Prog Ser 92:205-219

Clarke KR, Warwick RM (1994) Change in marine communithes: an approach to statistical analysis and interpretation Natural Environment Research Council, Plymouth

DeWitt TH, Levinton JS (1985) Disturbance, emigration, and refugia: how the mud snail, Ilyanassa obsoleta (Say) affects the habitat distribution of an epifaunal amphipod, Microdeutopus gryllotalpa (Costa). J Exp Mar Biol Ecol 92: $97-113$

Dittmann S (1996) Effects of macrobenthic burrows on infaunal communties in tropical tidal flats. Mar Ecol Prog Ser $134: 119-130$

Flach EC (1993) The distribution of the amphipod Corophium arenarium in the Dutch Wadden Sea: relationships with sediment composition and the presence of cockles and lugworms. Neth J Sea Res 31(3):281-290

Flach EC, de Bruin W (1993) Effects of Arenicola marina and Cerastoderma edule on distribution, abundance and population structure of Corophium volutator in Gullmarsfjorden Western Sweden. Sarsia 78:105-118

Grant J (1983) The relative magnitude of biological and physical sediment reworking in an intertidal community. J Mar Res 41:673-689

Hall SJ, Robertson MR, Basford DJ, Fryer R (1993) Pit-digging by the crab Cancer pagurus: a test for long-term, largescale effects on infaunal community structure. J Anim Ecol 62.59-66

Jones CG, Lawton JH, Shachak M (1994) Organisms as ecosystem engineers. Olkos 69:373-386

Murphy RC (1985) Factors affecting the distribution of the introduced bivalve Mercenaria mercenaria in a California lagoon-the importance of bioturbation. J Mar Res 43: 673-692

Murphy RC., Kremer JN (1992) Benthic community metabolism and the role of deposit-feeding callianassid shrimp. J Mar Res . 70:321-340

Myers AC $(197 \bar{f})$ Sediment processing in a marine subtidal sandy bottom community: II. Biological consequences. J Mar Res 35:533-647

Paine RT (1966) Food web complexity and species diversity. Am Nat 100:65-75

Peterson CH (1977) Competitive organization of the softbottom macrobenthic communities of Southern Calıfornia Lagoon. Mar Biol 43:343-359

Posey $\mathrm{MH}$ (1986) Changes in a benthıc community associated with dense beds of a burrowing deposit feeder. Callianassa californiensis. Mar Ecol Prog Ser 31:15-22

Retraubun AW, Dawson M, Evans SM (1996) Spatial and temporal factors affecting sediment turnover by the lugworm Arenicola marina (L.). J Exp Mar Biol Ecol 201:23-35

Rhoads DC, Young DK (1971) Animal-sediment relations in Cape Cod Bay, Massachusetts. 11. Reworking by Molpadia oolitica (Holothuroidea). Mar Biol 11:255-261

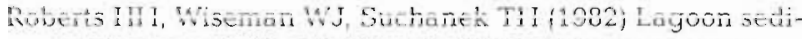
ment transport: the significant effect of Callianassa bioturbation. Proc 4th Int Coral Reef Symp, Manila. In: Gomez ED et al. ledsj Reef and man. Quezon City, p 459-465

Rowden AA, Jones MB, Morris AW (1998) The role of Callianassa subterranea (Montagu) (Thalassinidea) in sediment resuspension in the North Sea. Cont Shelf Res 18: $1365-1380$ 
Stambuis EJ, Schreurs CE, Videler JJ (1997) Burrow architecture and turbative activity of the thalassinid shrimp Callianassa subterranea from the central North Sea. Mar Ecol Prog Ser 154:155-163

Suchanek TH (1983) Control of seagrass communities and sediment distribution by Callianassa (Crustacea, Thalassinidea) bioturbation. J Mar Res 41:281-298

Swift DJ (1993) The macrobenthic infauna off Sellafield (north-eastern Irish Sea) with special reference to bioturbation. J Mar Biol Assoc UK 73:143-162

Swinbanks DD, Murray JW (1981) Biosedimentological zonation of Boundary Bay tidal flats, Fraser River Delta, British Columbia. Sedimentology 28:201-237

Tamaki A (1988) Effects of the bioturbating activity of the ghost shrimp Callianassa japonica Ortmann on migration of a mobile polychaete. J Exp Mar Biol Ecol 120:81-95

Thrush SF (1988) The comparison of macrobenthic recolonization patterns near and away from crab burrows on a sublittoral sand flat. J Mar Res 46:669-681

Thrush SF, Pridmore RD, Hewitt JE, Cummings VJ (1994) The importance of predators on a sandflat: interplay between seasonal changes in prey densities and predator effects. Mar Ecol Prog Ser 107:211-222

Townsend EC, Fonseca MS (1998) Bioturbation as a potential mechanism influencing spatial heterogeneity of North Carolina seagrass beds. Mar Ecol Prog Ser 169:123-132

Warwick RM, Gee JM, Berge JA, Ambrose W Jr (1986) Effects of the feeding activity of the polychaete Streblosoma

Editorial responsibility: Otto Kinne (Editor),

Oldendorf $/$ uhe, Germany bairdi on meiofaunal abundance and community structure. Sarsia 71:11-16

Warwick RM, Platt HM, Clarke KR, Agarde J, Gobin J (1990a) Analysis of macrobenthic and meiobenthic community structure in relation to pollution and disturbance in Hamilton Harbour, Bermuda. J Exp Mar Biol Ecol 138:119-142

Warwick RM, Clarke KR, Gee JM (1990b) The effect of disturbance by soldier crabs Mictyris platycheles $\mathrm{H}$. MilneEdwards on meiobenthic community structure. J Exp Mar Biol Ecol 135:19-33

Webster PJ, Rowden AA, Attrill MJ (1998) Effect of shoot density on the infaunal macro-invertebrate community within a Zostera marina seagrass bed. Estuar Coast Shelf Sci 47 : 351-357

Widdicombe S, Austen MC (1998) Experimental evidence for the role of Brissopsis lyrifera (Forbes, 1841) as a critical species in the maintenance of benthic diversity and the modification of sediment chemistry. J Exp Mar Biol Ecol 228:241-255

Wilson WH Jr (1981) Sediment-mediated interactions in a densely populated infaunal assemblage: the effects of the polychaete Abarenicola pacifica. J Mar Res 39:735-748

Woodin SA (1985) Effects of defecation by arenicolid polychaete adults on spionid polychaete juveniles in field experiments: selective settlement of differential mortality. J Exp Mar Biol Ecol 87:119-132

Zar JH (1984) Biostatistical analysis. Prentice-Hall, Englewood Cliffs, NJ

Submitted: May 20, 1999; Accepted: August 3, 1999

Proofs received from author(s): January 11, 2000 